\title{
Effective Improvement of Talents Management for Continuing of Managing Government
}

\author{
Ungsinun Intarakamhang ${ }^{1} \&$ Narisara Peungposop ${ }^{1}$ \\ ${ }^{1}$ Behavioral Science Research Institute, Srinakharinwirot University, Bangkok, Thailand \\ Correspondence: Ungsinun Intarakamhang, Behavioral Science Research Institute, Srinakharinwirot University, \\ Bangkok 10110, Thailand. E-mail: ungsinun@swu.ac.th
}

Received: September 18, 2013

Accepted: October 8, 2013 Online Published: December 31, 2013

doi:10.5539/ass.v10n1p124

URL: http://dx.doi.org/10.5539/ass.v10n1p124

\begin{abstract}
The Talent Management System or the HiPPS (High Performance and Potential System) was developed by the Office of the Civil Service Commission (OCSC) for 10 years since 2003 in Thailand. The purposes of this mixed methods research were 1) to develop of the causal relationship models of the effective talent management, 2) to investigate the percent of predict in each group, and 3) to study the current situation and to investigate strategies to improve the talent management to ensure continuity in government administration. The data were collected from five rating-scale questionnaires which the total -item correlation had been .2-.7. and $\alpha$ is .835-.909. The sample size were 109 talents, 96 coaches, and 100 human resource (HR) staffs who are responsible for the HiPPS system. Data was analyzed by LISREL and content analysis from 9-19 key persons in each 5 group such as executives, coaches, talents, HR staffs and former talents groups. The results indicated that 1) the causal relationship model of effective talent management for all groups were consistent with an empirical data at a strong level, 2) the person and work environment factors had positive effect and could be predicted in all groups regarding effective talent management for 48 percent in the talent group, 83 percent in the coaching group and 66 percent in the HR staff group, 3) the person and work environmental factors that influence the effective talent management, found that there are seven factors that impact in a positive way and two factors, such as positive attitudes toward the talent management, and organization commitment were a major factor that impacted directly positive influence on effective talent management, and 4) the problems of the effective talent management were 4.1) the executives didn't understand HiPPS or often change their executives, 4.2) the talents could not rotate as individual development plan and low effective coach system, 4.3) the talent development plan didn't clear and not support from organization. So, strategies of effective improvement should organize for administrative procedure as talent identifying, talent development, talent monitoring and evaluating, talent rewarding and performance management to share knowledge and innovation for continuing of public sector development.
\end{abstract}

Keyword: talent management, government administration, high performance, high potential, HiPPS system

\section{Introduction}

Measures for the administration of manpower in the public sector $(2552-2556 \mathrm{BE})$, based on the second development strategic, indicate that planning and monitoring of the utilization of manpower included guidelines for the implementation of the improved performance of manpower to meet the mission of the government and direction of development of the country by the Central Organization of Human Resource Management, in collaboration with federal agencies and relevant government agencies prepared to limit the performance and readiness for the mission. The government plans to encourage career development and has also made succession planning, which aims to build warehouse personal with outstanding achievements, successor's talent inventory for preparation for leadership, and also plans to prepare people to be ready for duty in the mission or in a position of strategic importance to the government, continuously. In addition, the OCSC has had a process in place to manage the talents for 10 years since 2003 in Thailand, whose aim is to be able to find people who have the knowledge and ability to support the advancement of modern science and to prevent problems associated with brain drain in the public system. Accordingly, the OCSC has introduced the concept of talent management used by this style, called the new administration strategy the high achievement or high performance official system, or the HiPPS (High Performance and Potential System). It includes a system of selection or recruitment, development, incentives or motivation, and keeping workers or retention. So the people, who are evolving, can 
provide the most appropriate personnel, with an emphasis on workplace learning through actual practice, rotating job schedules, coaching and learning through training, as well as the concept of compensation increases for achievers, in accordance with the characteristics of the job and the market price to avoid a gap between older people who are retiring and shortages in the talent ratio (Ungsinun et al., 2011). For this reason, it is necessary to execute the project to improve the performance management system of talent for the continuity of government management. The objective is to study strategies that may improve the efficiency of the talent management as well as to create a new generation of talent in the bureaucracy to ensure that government management is continuously driven. Finally, the government will develop a strong foundation and drive government agency success.

\section{Objectives of the Research}

1) To develop of the causal relationship models of personal and work environmental factors that influence the performance, talent management separated workers into three groups, such as civil servants as talents, group supervisors or coaches, and human resource officials who are responsible for the HiPPS system.

2) To investigate those factors which predict the performance of talent management separated into three groups, such as civil servants as talents, group supervisors or coaches, and human resource officials who are responsible for the HiPPS system.

3) To study the current situation and to investigate strategies to improve the talent management to ensure continuity in government administration.

\section{Research Framework}

The theoretical framework for this research is based on the Talent management in the public sector of the OCSC (2012), the Theory of Organizational Socialization, and Work Socialization, which is important so that a member has knowledge and skills of the profession (Professional socialization) and social culture in the organization (Organizational socialization) (Yung, 1994: 19). At this point, it will force people to learn about the attitudes and social norms, which are important factors in making them recognize their role and to complete their work. As a result, the research found that employees who receive social transfers from a quality organization will provide an efficient performance in both the quality of work and habits (Heck, 1995; Ostroff \& Kozlowski, 1993) and job satisfaction, for the other factors that influence the workplace climate and some personal factors that are experienced before they become members of the organization. (Muchinsky, 2003) Integrated with the concept of quality in the management of international manpower (Schuler \& Tarique, 2010), 360-degree assessment methods are used to gather data from multiple providers groups. Details are described as follows in Figure 1.

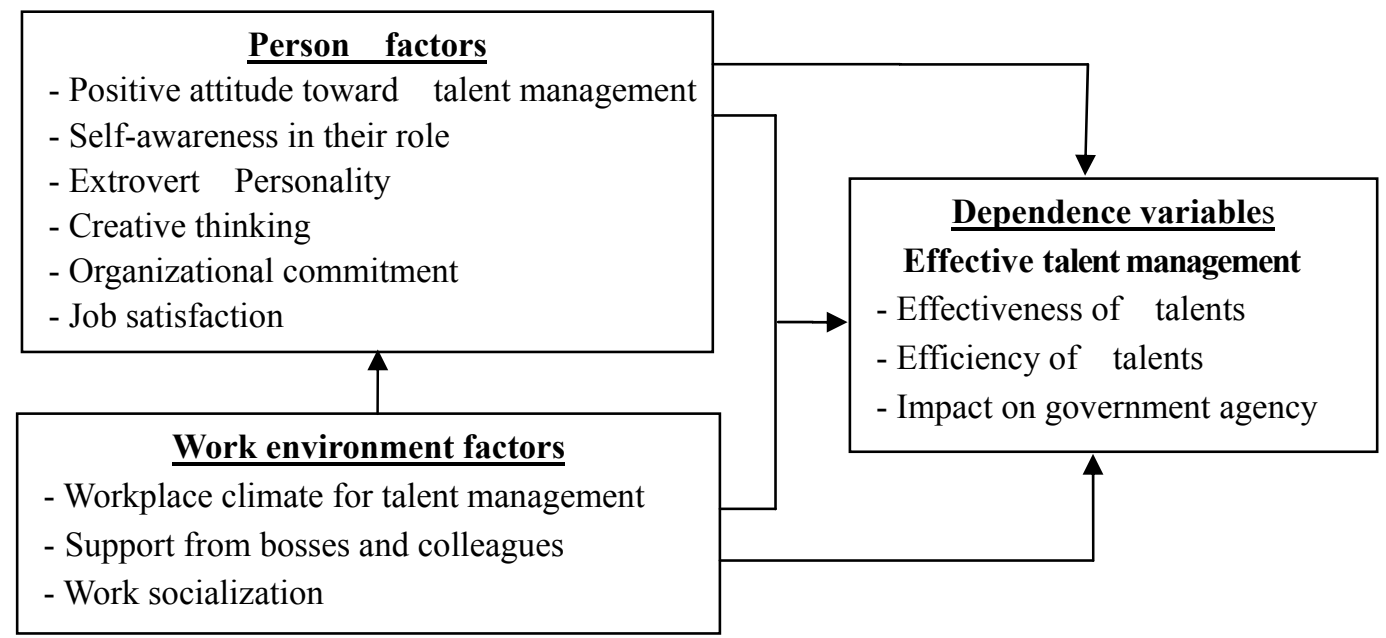

Figure 1. Conceptual framework in study the influence of the person and work environment factors related to the effective talent management

\section{Hypotheses of Research}

$\mathrm{H}_{1}$ : The causal relationship models of personal and work environmental factors in influencing the effective talent management separated workers into three groups, such as civil servants as talents, group supervisors or coaches, and personnel officials who are responsible for the HiPPS system, in accordance with the empirical data. 
$\mathrm{H}_{2}$ : Personal factors, such as self- awareness in their roles, attitudes toward talent management, extrovert personality organizational commitment and job satisfaction, and Work environmental factors, such as the workplace climate, support from bosses and colleagues, and work socialization have a positive influence all predicted effective talent management.

\section{Research Methodology}

This study employed a mixed methods using quantitative research in terms of the correlational research with the development of the causal model, followed by qualitative research of the multi- case study with the focus group to serve this research objective.

\subsection{Population}

The civil servants are capable and have high achievements working at the Departments, Ministry level, who are in the care of the HiPPS system or talent management system, including 540 participants who were talents representing 153 government agencies.

\subsection{Sample Size}

It has been calculated to analyze the quantitative data based on the concept of Tabachnick and Fidell (2001). It has been suggested that in the analysis of a causal relationship, there should be a sample size of 10 people per 1 estimate as the required parameters, and in this study, there is a required parameter estimate of 9 . Therefore, an acceptable sample size to minimize the data analysis should be equal to the $90-100 /$ group. In addition, we separate the data into two groups based on the type of data. For instance, 1) samples and quantitative data: there are three groups that have an adequate population size. 1.1) Supervisor group (Coaches): 96 participants. 1.2) Quality official group or talent group (Talents): 109 participants. 1.3) Groups of officers who are responsible for the talent management or human resources officials (HR staff): 100 participants. Furthermore, in terms of groups of participants who had qualitative data based on multi-case study, there were 5 cases or groups, such as 2.1) 14 Executive Vice-General or bosses, 2.2) 18 HR staff represented by varieties department, 2.3) 19 coaches of civil servants, 2.4) 13 talents and 2.5) 9 civil servants who are used to be talents.

\subsection{Research Process}

1) A review of literature related to the concept and talent management theory that describes the relationship between person and work environment factor.

2) Drafting a causal relationship model that impacts the effective talent management in relation to three sample groups: a) Groups of civil servants who perform the role of coaches; b) Groups of HR staff; and c) Groups of talents.

3) Defining the variable factors, which consist of two main groups. The first group represents personal factors, details as follows: a) Positive attitudes toward talent management; b) Self-awareness in their role; c) Extrovert personality; d) Job satisfaction; and e) Organization commitment. The second group, which is related to work environment factors, details as follows: a) The workplace climate that supports talent management; b) Support from bosses and colleagues; c) Work socialization regarding job performance; and d) the result of variable factors, such as the effective talent management, measured by three elements, for instance: Effectiveness of talents, Efficiency of talents, and Impact on government agency.

4) Validity for the instruments that have been developed based on the literature review and drafting the questionnaire. It had been evaluated for content validity from three experts and modified according to the experts' comments. It has been tried out with 58 new mentors, 30 HR staffs, and 45 new talents from December 2012 to January 2013. After the final revision of the questionnaire, there are nine variable factors, which address 150 items. Additionally, the corrected item-total correlation had been .2-.7. Finally, the instrument showed a high level of reliability $(\alpha)$ is .835-.909.

5) Data collection. The data were collected over a certain period of time (2013, Feb - Mar). Finally, there were 305 completed data that were represented and that met the minimum acceptable amount in order to analyze the data.

6) Data analysis. The LISREL program was used to test the hypothesis and interpret the content data. Additionally, qualitative data, such as the open-ended questionnaire and focus groups, were analyzed. 


\section{Research Results}

\subsection{Important Factors That Influence the Officials to Remain in the System Are Described in Detail Below}

Table 1. Important factors that influence 109 talents, $100 \mathrm{HR}$ staffs, and 96 coaches who remain in their organizations (choose many choices)

\begin{tabular}{lcccccc}
\hline \multicolumn{1}{c}{ Factors that make employees stay in the organization. } & \multicolumn{2}{c}{ Talents } & \multicolumn{2}{c}{ HR staffs } & \multicolumn{2}{c}{ coaches } \\
\cline { 2 - 7 } & $\mathbf{N}$ & $\%$ & $\mathbf{N}$ & $\%$ & $\mathbf{N}$ & $\%$ \\
\hline Type of work they do & 30 & 27.52 & 11 & 11.46 & 24 & 24.00 \\
Learning opportunities & 29 & 26.61 & 15 & 15.63 & 24 & 24.00 \\
Career opportunities & 22 & 20.18 & 12 & 12.50 & 22 & 22.00 \\
The people they work with & 20 & 18.35 & 19 & 19.79 & 17 & 17.00 \\
Base salary & 12 & 11.09 & 20 & 20.83 & 30 & 30.00 \\
Total compensation & 20 & 18.35 & 22 & 22.91 & 33 & 33.00 \\
Convenience ( transportation) & 8 & 7.34 & 8 & 8.33 & 17 & 17.00 \\
\hline
\end{tabular}

According to the information in Table 1, we can assume that the most important factor which affected participants in most of the groups to stay in the system or their organization was: talent groups endorsed the "Type of work they do" and Learning opportunities," whereas the other two groups were in agreement that "Total compensation" and "Base salary" were most important.

6.2 The Hypothesis Test Results in Term of a Causal Relationship Model of Effective Talent Management That Reveal with an Empirical Data at a Good Level Are Presented in Figure 2-4

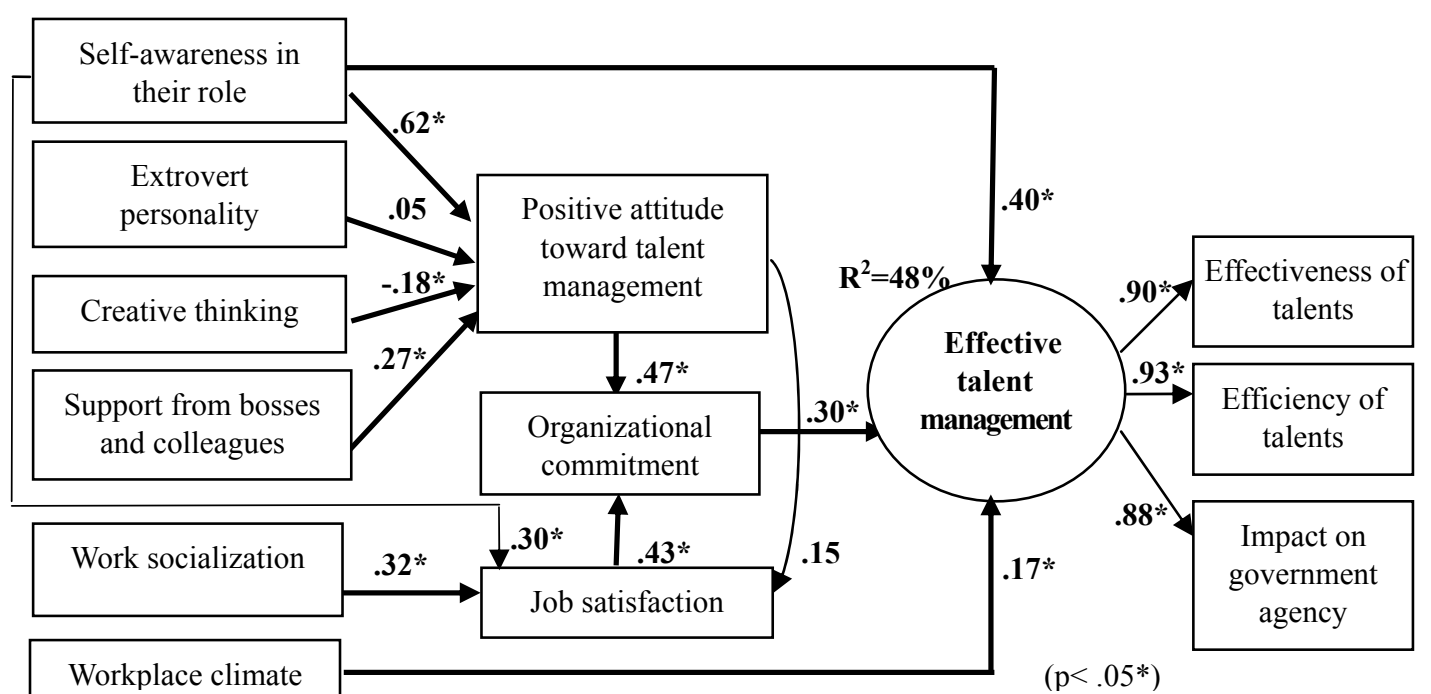

Figure 2. The causal relationship model of the effective talent management in a talent group 


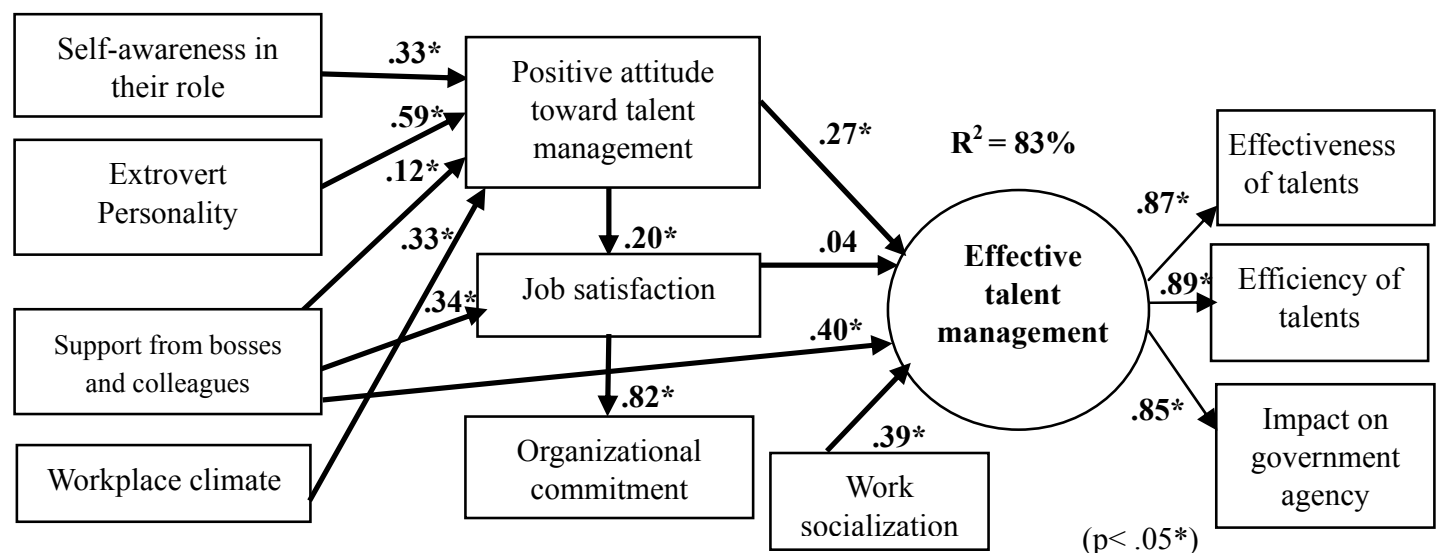

Figure 3. The causal relationship model of the effective talent management in a coaching group

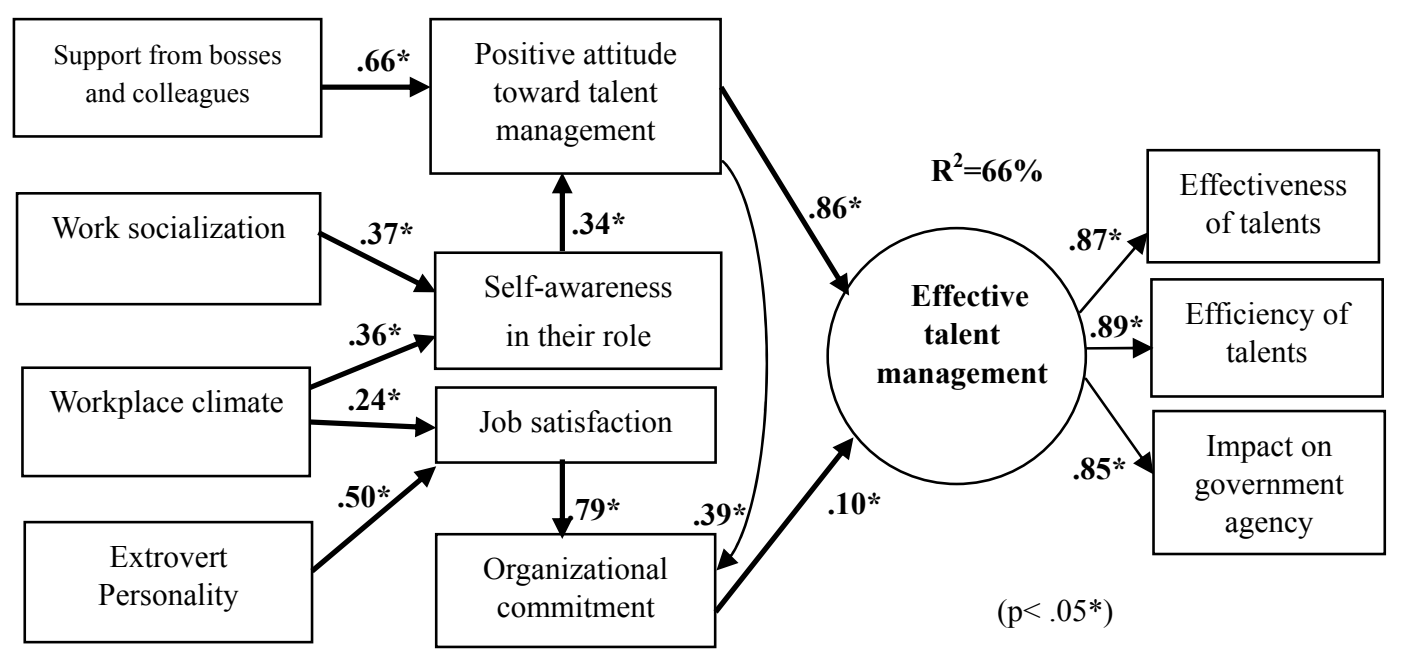

Figure 4. The causal relationship model of the effective talent management in a HR staff group

\subsection{The Research Results from the Focus Group Regarding Investigation of the Problem and Determining Strategies to Resolve the Problem}

For the study, the research has been conducted in related areas in both public and private sectors that are located in national and international areas. In addition, there was Meta analysis of the quantity and quality of study, so it could be assumed that the result of this study would be involved in the Executive Group, Middle manager group, mentor or coach, a group of HR staff who are responsible for the HiPPS system, and a group of talents. Thus, we could establish the summary model of this study, which could represent the efficiencies of talent management for continuity in the government organization. The causal integrated relationship model shows the variable factors of talent management, and the results of the system are detailed as follows: 


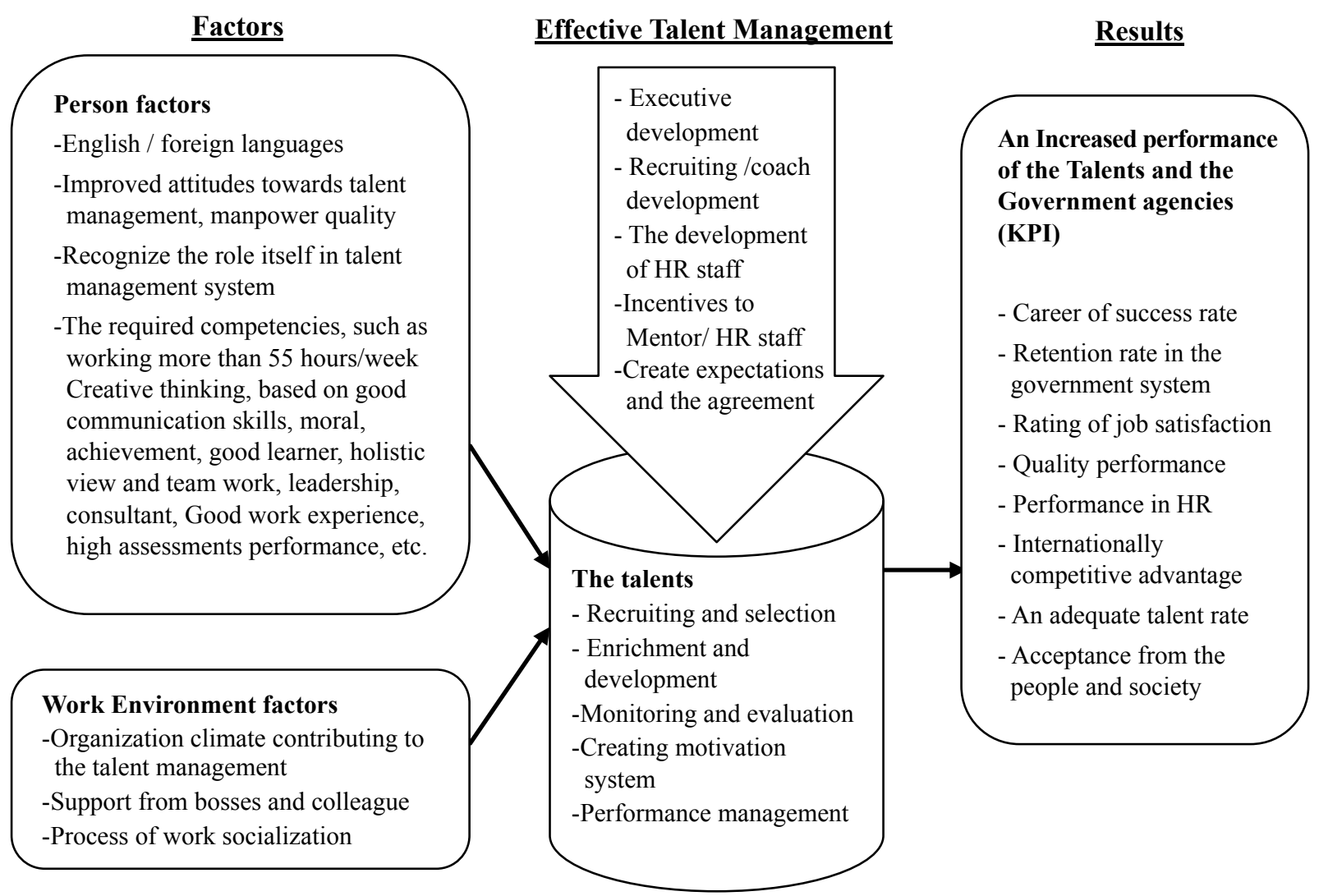

Figure 5. Model of effective talent management for continuing in public sector management

\subsubsection{Guidelines for Improving Recruitment and Selection Are Quality People (Identifying Talent)}

In accordance with a qualitative study on the specific issues of practice talent management, we found that in the current situation, the recruitment and selection recruiting issues, and in particular the qualifications of the candidate, are limited. So, the best practices for recruiting should be:

a) Should be able to adjust some qualifications, such as English language skills. As it used to be in a very good level in a criterion at this stage, the English language skills may be adjusted to a fine or medium level. This is because some of the candidates have expertise in the application but may not be good at English. However, some features should be added, such as passed the presentation of the project (Project presentation) together with, recruited good-mannered people. Furthermore, seeking the good manner in an indirect way, such as "How much that they love their organization, sacrifice is committed in a mental, moral, patience to estimate such an obstacle, as well as on the attitudes that people represent in the Talent management system.

b) In accordance with the recruitment methods issues, the OCSC should allow or enable the agency to participate in the qualifying criteria. It should be represented in two channels; for instance, first, to be able to apply it directly to the OCSC with the consent of the organization. The second channel should be applied through the central organization, and they should also have a chance to elect the candidate.

c) In addition, the system should introduce the project to the public. Also, officials who have high achievement should be invited to share their experience, data and information, as well as to prepare for the qualifying system, to those who are interested in applying.

d) In addition to the findings from the previous qualitative study, the recommendations from the review of documentation and research on related issues, we found that there is another interesting recruiting element, and this is the recruitment of people from the warehouse talent or the Talent pool. At this stage, the OCSC should be recruiting candidates from inside their organization based on the waiting list with candidates who have a good history. 


\subsubsection{Guidelines to Improve the Quality and Strength of the Talent Development (Developing Talent)}

Candidates in this group often had unique characteristics. Therefore, the management system for this group must be different from the others. The popular methods that used to be assigned to develop these people is that special assignments are to follow the executive manager, establish the master plan, job turnover, and training. There are two ways for the OCSC that are normally used to develop the talents. The first is the Experience Accumulation Framework: EAF, which is a tool to develop talent systematically, including an important activity, such as job turnover, and a task assignment that challenged the system and training the trainer and coaching etc. The second methods are the government development plans that remain in the system, a roadmap. According to the training plan, the OCSC had set up these criteria for all officials who are involved with the system of civil servants and have high achievement in all parties. By those involved, we mean they must be attending the course and pass the OCSC learning process group, such as training, seminars, indirect learning, both national and abroad, etc., as well as the group of Krung Thai banks management, which have two strategies of development, such as an individual development plan, and group development under the terms and conditions. The contract between employees and the official management board is to maintain the standard of Talent, and they will be aware of the expectations of managers towards us. Through establishing operational agreements (Performance agreement), those expectations will be a performance standard of Talent, which is much higher than the standard of general staff, and there will be a clear performance measure. To maintain the standard of Talent and moral development, we must take into account the responsibility to develop ourselves on behalf of the development organization.

From a qualitative study on issues of state barriers to strengthen and develop the quality of manpower and best practices of the Talent management system, leading to suggestions on issues to improve the quality and strengthen detail, which are as follows:

1) Job rotation for the talents; The main problem of job rotation is that civil servants are not qualified to work in the new agency in order to learn it efficiently. Because they are still on duty in their old workplace, in this case the agency should improve its process based on the issues as follows:

a) Should improve the rotation system for the candidate, such as cutting off the candidate's role from their old workplace, the same as finding the new person to substitute on their duty while they were on duty in the new place.

b) Sustainability framework should be reviewed annually to remain in line with common practice. At this stage, participants or whoever is involved in the civil servants should be able to share their need for the consideration, as well as allow the government to determine the number of years of experience and sustainability framework in order to upgrade the position of civil servants for a quality person to comply with the agency's context.

c) Should extend the learning time for accumulation of experiences of civil servants to a minimum of 3 years; as we agreed that the $1^{\text {st }}$ year should be a good learning period, the $2^{\text {nd }}$ year and the $3^{\text {rd }}$ year will be time for their productivity.

d) The OCSC should establish the framework for the fundamental requirement, especially for three main areas, such as plans career, financial career and human resource career, together with another one for an expert career. Therefore, candidates will experience efficiency in both management and common tasks, and finally, should be able to be integrated into a profession. In addition, it should make a specific experience for sustainability framework solutions in case that civil servant cannot follow the plan to accumulate experience.

2) Mentor and trainer system; From a qualitative study, we found that there are some problems in the trainer systems for the Talent management system. The possible reason is that we are lacking a training system for the mentor. In other words, it could be said that the mentors do not clearly know their jobs and sometimes appeared to be lacking a reinforcement methods to motivate talent in the candidates. Together with the gap in terms of a relationship between the civil servants and the trainer, the suggestions that make up this point were presented as follows:

a) Should have a two-way system for Mentoring and Coaching. The main Mentor should be assigned to the bosses whereas the coach or trainer could be an experienced government employee who possesses a good technique for teaching a new staff. It may not be necessary to be quality government employee as we could recruit them from the floor from people who either had experience or strong knowledge or were well-developed as role models.

b) Should establish the trainer system in parallel with the quality civil servants management by conducting training courses, such as short courses or long courses for improving the trainers' skill, in this case, conveyed with the knowledge and consulting skill. At the same time, we could prepare them to understand the system. In 
terms of the proportion of trainers: Civil servants should be 1 person per 1 unit in a workplace as it does not necessarily have to have a high number of trainers, but should instead be focused on the standard of the trainer. The trainer should be ready for broadcast and should have the ability to extract the potential of talents.

c) Should give incentives to the trainer as compensation (Top up). In other words, the organization should give incentives (money) for working an extra job or payment in something else rather than money, such as the announcement to the public of the trainer achieving a higher position.

3) The government development plans; The civil servants mostly had a framework for their quality and experience on their own. On the other hand, the stakeholders that are involved with a bureaucracy, such as the executive manager or supervisors, should take responsibility to follow the rules and regulations seriously. The OCSC should set up the curriculum for all staff to participate as a basis for the holistic implementation of Talent management. Therefore, we recommend that the stakeholder, such as the junior supervisor, mentor, civil servants, or those responsible for the system should attend the orientation or training to learn the rules and guidelines of the project as a fundamental requirement.

6.3.3 The Guidelines for Improving, Monitoring and Evaluating the Quality of Talents (Monitoring and Evaluating Talent)

The evaluation system appears to be an obstacle of the talent management system, as the way that we evaluate does not correspond to reality based on the individual. The OCSC had designated that all of the quality must at least pass the evaluation at the "very good" level. In fact, some of the qualities passed it under the minimum criteria. Accordingly, the mentor may not evaluate according to the fact, which is not fair to the other one that may not be included in this quality group. Therefore, we should allow the mentor to work independently regarding performance assessment. In addition, it should be on time for setting up an obvious regulation for performance assessment criteria.

\subsubsection{Adjust the Guidelines for Reinforcing an Incentive (Rewarding Talent)}

The popular methods that have been used in various organizations for reinforcement is to create incentives, providing compensation, rights welfare for agencies to award an annual lump sum, etc. Strengthening for motivation of the OCSC is to give an advantage on the career path and provide compensation for their colleagues. According to the results of the study, we found that motivating the stakeholder to maintain the system "is not the issue," because the most common reason that quality civil servants were still working in the unit were dependent either on the opportunity to develop their carrier path or the feeling of challenge in their job rather than the cause of salary or compensation. Whereas the stakeholder, such as the mentor or trainer and the officials responsible for the system, the agency's compensation and salary would be an important factor that influenced them to remain in the system. Thus, the recommendation regarding incentives that could improve the Talent management system was shown as follows:

1) In a group of quality civil servants, those working for the OCSC should be surveyed regarding their requirements so the OCSC could be able to create any rewards based on their needs.

2) In the mentor or trainer group, and among officials responsible for the system, the OCSC should be concerned with and reinforced to act as to what motivates them to work in the system: for example, receiving more compensation from the burden in case they take an advantage for more responsibility than usual or give them a pride to the public etc.

\subsubsection{Portfolio Management (Performance Management)}

In the government, we found that giving priority to the results from the administration was limited for uses, unlike the private organization that gave high attention to this procedure. As shown in the study of ASTD (American Society for Training and Development) cited in Sukanya (2011), in a survey of the organization's activity around the world, they defined an activity or management strategy for quality of the talent system in order of the most important factor and presented them by percentages, such as: 1) Performance management, 2) Learning/training 3) Leadership development 4) Employee development high potential 5) Recruitment 6) To create engagement 7) Compensation and rewards 8) Succession planning, and 9), Planning, career Planning, at $63.7 \%, 61.7,59.1,52.8,43.2,40.039 .9,39.2$, and 34.8 , respectively. These may be different from the Thai Government and the OCSC, as we pay attention to learning/training, the development of high-potential employees, recruiting, career path or career of success, and career planning for succession candidates, as the first priority may be due to restrictions of the Government's budget, the nature and culture of the organization, which does not focus on profit. Therefore, the lack of innovation in the work or official was used for internal development rather than international competition. An exception would be in some organizations that had a 
mission for global competition and could require the project to be part of their management, such as the Revenue Department.

\subsubsection{Recommendations to the Talent Management Systems}

The systems based on the previous to be able to work continuously and be sustainable. It needs to be linked with and integral to some similar courses, such as change leader course and efficient civil servants, those who have high achievement performance. Accordingly, it must emphasize the developing skills of talent continuously, even those people who have resigned from the course, such as a quota for ex-civil servants to participate in training or sharing their experience with the younger staff, etc.

\section{Conclusions}

In terms of the quantitative data, we found that it was in accordance with the hypothesis.

1) The causal relationship model of the effective talent management for talent group was consistent with the empirical data at a strong level (Chi-Square $=49.76, \mathrm{df}=35, \mathrm{P}$-value $=0.5044, \mathrm{RMSEA}=0.063$ ).

2) The causal relationship model of the effective talent management in the coaching group was consistent with the empirical data at a strong level (Chi-Square $=36.24, \mathrm{df}=24, \mathrm{P}$-value $=0.05202, \mathrm{RMSEA}=0.078$ ).

3) Causal relationship model of the effective talent management in HR staff group was support with the empirical data in a good level. (Chi-Square $=43.39, \mathrm{df}=35, \mathrm{P}$-value $=0.10649, \mathrm{RMSEA}=0.062$ ).

4) The person and work environment factors had positive effects and could be predicted in all groups regarding effective talent management. Further details were described as follows:

In the talent group, we found that both person and work environment factors could predict the effective talent management for 48 percent, which Self-perceived role, Organization commitment, and Workplace climate had a direct positive influence on effective talent management with effect size of $.40, .30$, and .17 , respectively $(\mathrm{p}<.05)$ and the other indirect factors, including 1.1) Support from bosses and colleagues; 1.2) Work socialization; 1.3) Recognizing their role; 1.4) Creativity; 1.5) Attitudes toward the talent management; and 1.6) Job satisfaction. All of these factors with the influence coefficients are at .04, .04, .14, - .08, .16, and .13, respectively $(\mathrm{p}<.05)$.

In the coaching group, we found that both person and work environment factors could predict the effective talent management for 83 percent, which Social support from bosses and colleagues, Work socialization, Positive attitude toward the talent management, Job satisfaction that had a direct positive influence on effective talent management with effect size of $.40, .39, .27$, and .04 , respectively $(\mathrm{p}<.05)$, and indirect factors that are Recognize their role, and Extrovert personality with the influence coefficients at 0.09 and 0.16 , respectively $(\mathrm{p}<.05)$.

In the HR staff group, we found that both person and work environment factors could predict the effective talent management for 66 percent as same as the other groups. In addition, Social support from bosses and colleagues, Work socialization, and Recognize their role with the influence coefficients at $0.55,0.10$ and 0.28 , respectively $(\mathrm{p}<.05)$.

The best practices in workforce management and quality of service based on feedback from the focus group results details are describe below.

a) The process of recruitment

- A review of the recruitment criteria on HiPPS / selection with the experience accumulation recommend the same direction, and the agencies or organization should be involved in recruiting process for HiPPS.

- Equal opportunity to anyone to apply evenly.

- Some government agencies or organizations are preparing for the English test with the applicants.

- Promote information by focusing on benefits of the career paths.

- Encourage applications and open the invitation for the HiPPS to broadcast an experience for the next generation.

b) Mentor System must be trained and prepared for a nanny in the government organization.

c) Teaching jobs / giving assignments.

- An assignment on the basis of individuals' self-directed learning.

- The assignment should be a challenge to speed up timing and creative thinking. Therefore, at the beginning stage, the job should be a complicated task. 
d) Talent management system. The model of HiPPS should be introduced and applied in general for the civil servant who had a good performance. Nevertheless, the candidates are not interested in applying in the HiPPS central area.

e) To study for improving the talent management to ensure continuity in government administration, showing guidelines of administrative procedure summarized figure as follows:

- There is to take advantage of the work of talent, more may be the main authority in the management of Government intellectual rights or coordinated with central agencies to develop beneficial to compete internationally.

- There are conferences or forums to share knowledge and exchange between Government innovations. To develop beneficial knowledge, both at the national and international level.

- To retain and motivate quality people by government officials who are surveying needs and what the quality people expect in terms of continued advancement in the profession.

- Reinforcement mentor/ trainer, and the officials responsible for such a system to receive compensation on the rise, or praising the Declaration promoted.

- Trainer power independent performance assessment.

- There is a performance evaluation criterion in the dimension of time to clear.

- Job rotation of talent quality.

- Improved circulation of talent quality, cut off from the affiliation.

- Should review the sustainability framework, the experience of civil servants as quality people, annually to reflect practice in a Republican context.

- Extend time of gaining experience for the quality civil servant.

-Establish the right type of professional career for the quality civil servant to be able to get along with the strategies of the organization.

-Mentor of Coaching system.

-Should have both system Mentoring and Coaching.

Talent developing

-Set up either short or long course training for mentor skills.

-Should reward the mentor either in money value or nothings of different value.

- Efficiency plan for quality civil servant.

-Should be defined as mandatory; those involved with the system of administration of talent. Must attend training and orientation on the system of civil servants who have higher achievement to receive information about rules and guidelines of the project.

- Adjust and add some qualifications for quality people.

- Provide a chance for the stakeholder to establish the criteria for the recruitment and selection.

- Promotion system, civil servants who had achievement by opening the

Talent rewarding management arena invites civil servants to share their experiences.

- Recruiting candidates from the warehouse (Talent pool).

Figure 6. Guidelines to improve the Talent management according to the mechanisms

\section{Discussion}

The achievement of the talent management depends on the system that represents the four stages of recruitment and selection, such as talent identification, talent development, talent monitoring and evaluation, and talent rewarding, as they were adopted from the OCSC model (Ungsinun et al., 2011), which consists of five steps, 
including setting up the competency, evaluation and selection, planning for development of the replacement, a development step, and finally, the treat and remaining benefits from the manpower. These were in accordance with the previous study of Sukanya (2011: 30), which introduced the four steps of manpower management, such as 1) to search for the talent in an organization that they would like to develop (Identify Talent) by Competency Model of the Organization; 2) Developing Talent was focused on a competency and development plan for a career of success in conjunction with the Succession Planning for the important positions; 3) Evaluating Talent; and 4) Rewarding Talent at this stage, to empower the participant to create an innovation for the organization that would be fundamental, which is supported by the recent study of Krittin (2009), which has compiled some case studies from the top five management, quality of private sector organizations in Thailand, including: 1) Shin Corporation Public Company Limited, 2) the CISCO 3) The Airports of Thailand Plc. (Ltd) 4) Siam Cement Group (Thailand), and 5) Bangkok Insurance Public Company Limited. Additionally, all of the above had the same recommendations for the Talent management, such as, 1) To recruit and select talented people; 2) To develop talented people; 3) To reward and treat talented people by applying this method to the organization's strategic plan. On the other hand, this compares with the international research study we found of Phongpiboon and Wittapon (2009), when representatives from the Mercer organizations had introduced the procedure of the quality management system similar to the OCSC model. In that the first step is to identify a means to define and identify the performance of talents; the second step is to attract, which refers to recruitment and selection of the talents; the third step is to integrate and measure, which is referred to as the Talent management; and the fourth step is to develop, which means to develop talent management. The fifth step is to motivate and retain, which means to monitor the talents utilization. Nevertheless, the international Meta analysis of Tarique and Schuler (2010) based on the Global Talent Management (GTM) model was presented in a manner which displayed causes and effects of the system of Talent management, beginning with external factors, such as structure of the world population, advantage in the competition, whereas internal factors including setting, culture, etc., which transmits to the systems and are comprised of three stages, including attracting people, finding talent, and retaining talent. However, system development was focused on the Global Talent Management (GTM), which is normally measured by 1) Improving efficiency in HR will be considered in three main issues, for instance, establish adequate guidelines and talent management and create a scorecard as an indicator of talent management; 2) The advantages of competition; and 3) To set up the right position the organization, at the right time, along with the motivation and the competencies that are fundamentally required at all levels and in all positions in the organization. In other words, the organization has employees who are in the right location at the right time as required. However, for the key performance indicators, or "KPI," the talent management in Maharaj Nakorn Hospital Chiang Mai (2009) was measured by the indicators 1) Increase of work quality in talent group; 2) Satisfaction rate of the talent group; and 3) The turnover rate of resignation of the talent group.

\section{The Suggestions}

According to the analysis factors that influence talent management focused on the study of person and work environmental factors that influence the effective talent management, we found that there are seven factors that impact directly in a positive way. Furthermore, some factors, such as "positive attitudes toward the talent management," play an influential role in both groups (coaches and HR staff) whereas, "organization commitment" was a major factor that impacted on a group of talents and a group of HR staff those response for the HiPPS system. So, The OCSC and the other government organizations should take priority beginning with establishing these two factors as a basic requirement for recruiting and selecting candidates into the system. Additionally, the factor related to an evaluation scale or the implementation of activities that reflect a feature or by using a query, from managers and colleagues for evaluation. The other factors may also be important as a secondary flow in a qualifying criteria or developing feature to the workplace environments that finally contribute to the Talent management.

Considering only the talent group, it was found that their role recognition was the most important factor that influenced attitudes toward good talent management $(\beta=\mathrm{P}<.05, .62)$, and work socialization was the highest influence based on job satisfaction $(\beta=.32, \mathrm{P}<.05)$. At this stage, the OCSC should clearly understand and convey this information through orientation for new employees. In the coach group, we found that performance personality had the highest impact on positive attitudes toward talent management $(\beta=.59, \mathrm{P}<.05)$, followed by recognizing their roles $(\beta=\mathrm{P}<.05, .40)$. The Executive Government should consider this feature as an important character for mentoring. Furthermore, in a group of civil servant responses to the system, we found that support from bosses and colleagues has a great influence on attitudes toward the maximum of talent management ( $\beta$ $=.66, \mathrm{P}<.05)$ and attitudes that influence the Talent management, maximum performance, and high talent management $(\beta=.86, \mathrm{P}<.05)$. As a result, the bosses of the HR staff responsible for the system should provide 
and support any resources, data, and even moral support, so that the officials will have positive attitudes toward talent management systems accordingly.

For the improvement of talent management system mentioned above, the person who works in the talent management system as the part of HiPPS should be involved to enhance the system effectively. In this part, the suggestions on effective improvement of talent management for continuing of managing government classified by group of related people, are shown in table 2

Table 2. Suggestions on effective improvement of talent management for continuing of managing government classified by group of related people

\begin{tabular}{ll}
\hline \multicolumn{1}{c}{ Groups } & \multicolumn{1}{c}{ Suggestions } \\
\hline Executive & -Making MOU on working cooperation between the talent and the chief. \\
chief & -Performing mentor who teaches, suggests, and acts like a role model in work. \\
& -Allowing flexible time and rules/conditions that support the talent staff to create a new work or \\
& innovation.
\end{tabular}

Coach $\quad$-Performing coach who teaches in work life and acts like a role model in work -Enhancing work competency by participating in any training programs and working with executive chief both in and out of the organization.

-Making their own career path clearly.

Talent -Developing talent's competency by self-learning and doing challenging work.

-Connecting and extending knowledge by knowledge management and knowledge sharing with HiPPS network.

-Creating the creative and innovative work by cooperating with private and public organization or by exchanging the innovative work with nation and international organization.

HR staff -Building the special HR team that work for only HiPPS.

-Building the talent unit in each government agency. As for, HR division that is strong and ready should move forward firstly.

-Motive system, development system and career path for HR staff should be set.

OCSC -Providing the continuing training programs for any groups that related to HiPPS. Social media network to announce the programs should be used. E-learning and social media to support life-long leaning should be allocated.

-Building supervisor team for following up, evaluating management system, giving advice, solving problems and encouraging executive chief to consider and participate in the system. The component of the supervisor team should consist of an OCSC officer, the representative of a government division, and an expert from outside the organization. The duration of supervision should be 3 times per year.

-Developing EAF to be the agreement or working standard that is able to effective practice and evaluate.

-Improving and amending law and regulation that is flexible in time, space, and working context.

-Producing working motives to fit all groups of people. For example, talent staff needs opportunity of career progression, doing challenging work, and developing their own competency. As for, coach and HR staff, supporting with salary and payment is necessary.

-Allocating the learning system across the organization. Also, allowing talent staff to work with executive chief from private organization.

-Enhancing the selection and recruitment system. Project presentation or innovative work presentation should be a criterion for recruitment.

-Providing development guidelines for government staff to be an eager to learn. The sample of activity to support eagerness to learn is book briefing or book club sharing.

-Building and developing lecturer team which consists of executive chiefs, coach, talents staff, HR staff, OCSC officers, to introduce HiPPS for the public.

-Creating environment of development and promoting talent's career path.

-Providing the knowledge sharing stage between the talents from each government division. Also, building the group of talent network to invent innovative works and projects by integrating project between government divisions and pushing integrative projects to the international competition. 


\section{Acknowledgements}

This study was part of talent management system development financially supported by the Office of the Civil Service Commission (OCSC), Prime Minister's Office in Thailand.

\section{References}

Creswell, J. W., \& Plano Clark, V. L. (2011). Designing and conducting mixed methods research (2nd ed.). Thousand Oaks, CA: Sage Publications.

David, G. C., \& Kamell, M. (2009). Strategic talent management: A review and research agenda. Human Resource Management Review, 19, 304-313. http://dx.doi.org/10.1016/j.hrmr.2009.04.001

Fawcett, D. (2002). Mentoring, what it is and how to make it work. AORN Journal, 75(5), 950-954. http://dx.doi.org/10.1016/S0001-2092(06)61459-2

Greenberg, J., \& Baron, R. A. (2003). Behavior in Organization. Boston: Allyn and Bacon.

Hair, J. F. J., Black, W. C., Babin, B. J., \& Anderson, R. E. (2010). Multivariate Data Analysis with Reading. NJ: Prentice-Hall.

Heck, R. H. (1995). Organizational and professional socialization: Its impact on the performance of new administrators. The Urban Review, 27(1), 31-49. http://dx.doi.org/10.1007/BF02354334

Intarakamhang, U., Kittipichai, W., Hanpachern, C., \& Kuljittiprasit, P. (2011, May). Success Results of High Performance and Potential System (HiPPS) Administration of Thai Government Departments. Asian Social Science, 7(5), 42-52. http://dx.doi.org/10.5539/ass.v7n5p42

Joreskok, K. G., \& Sorbom, D. (1993). LISREL 8: Structural Equation Modeling with the SIMPLIS Command Language. Chicago: Scientific Software International. Inc.

Judge, A. T., Heller, D., \& Mount, K. M. (2002). Five-factor model of personality and job satisfaction: A metaanalysis. Journal Applied Psychology, 87(3), 530-541. http://dx.doi.org/10.1037/0021-9010.87.3.530

Krittin, K. (2009). Do not want to lose talent in the organization. Bangkok: HR center publication.

Kutilek, L. M., \& Earnest, G. W. (2001). Supporting professional growth through mentoring and coaching. Journal of Extension, 39(4). Retrieved December 9, 2002, from http://www.joe.org/joe/2001 august/rb1.php

Lewis, R. E., \& Heckman, R. J. (2006). Talent management a critical review. Human Resource Management Review, 16(2), 139-154. http://dx.doi.org/10.1016/j.hrmr.2006.03.001

Mai, M. N. H. C. (2009). Talent management Project. Retrieved January 20, 2013, from http://www.med.cmu.ac.th/hospital/nis/pdf/talent.pdf

Meyer, J. P., Allen, N. J., \& Smith, C. A. (1993). Commitment to organizations and occupations: Extension and test of a three-component conceptualization. Journal of Applied Psychology, 78(4), 538-551. http://dx.doi.org/10.1037/0021-9010.78.4.538

Muchinsky, P. M. (2003). Psychology Applied to Work: An Introduction to Industrial and Organizational Psychology (7th ed.). North Carolina: Thomson Wadsworth.

Ostroff, C., \& Kozlowski, S. W. J. (1992). Organizational socialization as a learning process: The role of

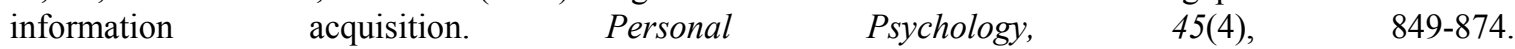
http://dx.doi.org/10.1111/j.1744-6570.1992.tb00971.x

Rassametummachot, S. (2011). The Effective Performance Appraisal Handbook. Bangkok: National Productivity Institute.

Robert, E. L., \& Robert, J. H. (2006). Talent management: A critical review. Human Resource Management Review, 16, 139-154. http://dx.doi.org/10.1016/j.hrmr.2006.03.001

Sak-Udomkajorn, P., \& Jawjit, W. (2009). Improving organization performance through Talent management and employee engagement. Lecture paper.

Schaffer, M. A. (2005). Social Support. Philadelphia: Lippincott.

Schweyer, A. (2004). Talent Management: Best Practices in Technology Solutions for Recruitment, Retention and Workforce Planning. Canada: Tri Graphic Print, John Wiley \& Sons.

Spector, P. (1997). Job Satisfaction: Application, Assessment, Causes, and Consequences. Thousand Oaks, CA: 
Sage Publications.

Tabachnick, B. G., \& Fidell, L. S. (2001). Using Multivariate Statistics. New York: Harper Collins college Publishers.

Tarique, I., \& Schuler, R. S. (2010). Global talent management: Literature review, integrative framework, and suggestions for further research. Journal of World Business, 45(2), 122-133. http://dx.doi.org/10.1016/j.jwb.2009.09.019

The Office of the Civil Service Commission (OCSC). (2005). Vision, mission, goals, and strategies. Retrieved March 2, 2012 from http://www.ocsc.go.th/ocsccmsen/View1/view.jsp?contentID=CNT0000028

The Public Sector People Managers' Conference. (2010). Talent Management. Retrieved March 21, 2010 from http://publicsectorhrpodcast.co.uk

Yung, H. H. P. (1994, October). Socialization, role Conception Decision Making: A Literature Review. AJNS, 20, $18-25$.

\section{Copyrights}

Copyright for this article is retained by the author(s), with first publication rights granted to the journal.

This is an open-access article distributed under the terms and conditions of the Creative Commons Attribution license (http://creativecommons.org/licenses/by/3.0/). 